\title{
Editorial for the special issue on micro-/nanorobotics
}

\author{
Hongsoo Choi ${ }^{1 *}$, Wen J $\mathrm{Li}^{2}$ and Li Zhang ${ }^{3^{*}}$
}

\section{Editorial}

Micro-/nanorobotics is an interdisciplinary field between micro-/nanotechnology and robotics. In principle, a robotic agent with a dimension in the range between $1 \mu \mathrm{m}$ to $1,000 \mu \mathrm{m}$ and $1 \mathrm{~nm}$ to $1 \mu \mathrm{m}$ can be considered as a microrobot and a nanorobot, respectively, and hence, the scaling law plays an important role for these miniaturized devices. Micro-/nanorobotics is the field to design and manufacture minute objects, to understand the properties and performance of robots at small scales, as well as to implement those tools/systems for various applications, including biology, biomedicine, and environments, with intelligence and autonomy. Therefore, the synergy of researchers with different backgrounds, such as physics, chemistry, robotics, materials science, micro-/nanotechnology, and computer science, is required for the advancement of this emerging field.

Herein, it is our great pleasure to present this special issue, entitled 'Micro-/Nanorobotics', for Robotics and Biomimetics, which includes some latest progress of this emerging but fast-growing field. Moreover, it is expected that this special issue could stimulate the future R\&D of micro-/nanorobotics. The research articles and reviews in this special issue include topics ranging from remotely actuated micromachines and microrobots to micro-/ nanorobotic manipulation tools and systems.

Last but not the least, we would like to take this opportunity to thank all the authors for their hard work on this special issue, the strong support from Prof. Yunhui Liu, the editor-in-chief of Robotics and Biomimetics, as well as the assistance and advice from the publisher Springer.

\footnotetext{
* Correspondence: mems@dgist.ac.kr; lizhang@mae.cuhk.edu.hk

'Department of Robotics Engineering, Daegu Gyeongbuk Institute of Science and Technology (DGIST), 50-1 Sang-Ri, Hyeonpung-Myeon, Dalseong-Gun, Daegu 711-873, Republic of Korea

${ }^{3}$ Department of Mechanical and Automation Engineering, The Chinese University of Hong Kong, Room 318, William M.W. Mong Engineering Building, Shatin NT, Hong Kong, SAR, China

Full list of author information is available at the end of the article
}

\begin{abstract}
Author details
${ }^{1}$ Department of Robotics Engineering, Daegu Gyeongbuk Institute of Science and Technology (DGIST), 50-1 Sang-Ri, Hyeonpung-Myeon, Dalseong-Gun, Daegu 711-873, Republic of Korea. ${ }^{2}$ Department of Mechanical and Biomedical Engineering, City University of Hong Kong, AC1-P6320, Academic 1, 83 Tat Chee Avenue, Kowloon Tong, Hong Kong, SAR, China. ${ }^{3}$ Department of Mechanical and Automation Engineering, The Chinese University of Hong Kong, Room 318, William M.W. Mong Engineering Building, Shatin NT, Hong Kong, SAR, China.
\end{abstract}

Received: 22 December 2014 Accepted: 22 December 2014 Published online: 07 March 2015

\section{Submit your manuscript to a SpringerOpen ${ }^{\circ}$ journal and benefit from:}

- Convenient online submission

- Rigorous peer review

- Immediate publication on acceptance

- Open access: articles freely available online

- High visibility within the field

- Retaining the copyright to your article

Submit your next manuscript at springeropen.com

\section{空}

(C) 2015 Choi et al.; licensee Springer. This is an Open Access article distributed under the terms of the Creative Commons Attribution License (http://creativecommons.org/licenses/by/4.0), which permits unrestricted use, distribution, and reproduction in any medium, provided the original work is properly credited. 